\title{
Factors predicting the use of therapeutic hypothermia and survival in unconscious out-of-hospital cardiac arrest patients admitted to the ICU
}

TW Lindner ${ }^{1 *}$, J Langørgen ${ }^{2}$, K Sunde $^{3}$, Al Larsen ${ }^{4,5}$, JT Kvaløy $^{6}$, JK Heltne ${ }^{5,7}$, T Draegni $^{8}$ and E Søreide ${ }^{1,5}$

\begin{abstract}
Introduction: Therapeutic hypothermia (TH) after out-of-hospital cardiac arrest (OHCA) was adopted early in Norway. Since 2004 the general recommendation has been to cool all unconscious OHCA patients treated in the intensive care unit (ICU), but the decision to cool individual patients was left to the responsible physician. We assessed factors that were associated with use of $\mathrm{TH}$ and predicted survival.

Method: We conducted a retrospective observational study of prospectively collected cardiac arrest and ICU registry data from 2004 to 2008 at three university hospitals.

Results: A total of 715 unconscious patients older than 18 years of age, who suffered OHCA of both cardiac and non-cardiac causes, were included. With an overall TH use of $70 \%$, the survival to discharge was $42 \%$, with $90 \%$ of the survivors having a favourable cerebral outcome. Known positive prognostic factors such as witnessed arrest, bystander cardio pulmonary resuscitation (CPR), shockable rhythm and cardiac origin were all positive predictors of TH use and survival. On the other side, increasing age predicted a lower utilisation of TH: Odds Ratio (OR), 0.96 ( $95 \% \mathrm{Cl}, 0.94$ to 0.97); as well as a lower survival: OR 0.96 ( $95 \% \mathrm{Cl}, 0.94$ to 0.97$)$. Female gender was also associated with a lower use of TH: OR 0.65 ( $95 \% \mathrm{Cl}, 0.43$ to 0.97); and a poorer survival: OR 0.57 (95\% Cl, 0.36 to 0.92). After correcting for other prognostic factors, use of $\mathrm{TH}$ remained an independent predictor of improved survival with OR 1.91 (95\% Cl 1.18-3.06; $P<0.001$ ). Analysing subgroups divided after initial rhythm, these effects remained unchanged for patients with shockable rhythm, but not for patients with non-shockable rhythm where use of $\mathrm{TH}$ and female gender lost their predictive value.
\end{abstract}

Conclusions: Although TH was used in the majority of unconscious OHCA patients admitted to the ICU, actual use varied significantly between subgroups. Increasing age predicted both a decreased utilisation of TH as well as lower survival. Further, in patients with a shockable rhythm female gender predicted both a lower use of TH and poorer survival. Our results indicate an underutilisation of $\mathrm{TH}$ in some subgroups. Hence, more research on factors affecting TH use and the associated outcomes in subgroups of post-resuscitation patients is needed.

Keywords: Out-of-hospital cardiac arrest, therapeutic hypothermia, survival, age, gender, intensive care

\footnotetext{
* Correspondence: lindnerthomas@hotmail.com

'Department of Anaesthesiology and Intensive Care, Stavanger University Hospital, Norway

Full list of author information is available at the end of the article
}

\section{Introduction}

Based on two landmark publications on mild therapeutic hypothermia (TH) in out-of-hospital cardiac arrest (OHCA) patients $[1,2]$, the International Liaison Committee on Resuscitation (ILCOR) in 2003 issued an advisory statement recommending $\mathrm{TH}$ for all unconscious OHCA patients with return-of-spontaneous circulation (ROSC) and an initial shockable rhythm [3]. 
The committee also suggested cooling unconscious patients with an initial non-shockable rhythm. Hospitals in Norway were early adopters of this new post-resuscitation therapy [4-7]. Since 2004, the Norwegian medical consensus was to provide $\mathrm{TH}$ to all unconscious $\mathrm{OHCA}$ survivors, regardless of the cause of cardiac arrest, initial rhythm and age, as long as active intensive care unit (ICU) treatment was considered [8]. The first Norwegian experiences with the use of $\mathrm{TH}$ were published in 2006 to $2007[5,7,9]$. Although TH was part of a standardised treatment protocol [7], individual therapy was left to physician discretion and bedside judgment. Therefore, treatment in individual patients may not always have followed these national recommendations. On the other hand, the evidence for the use of $\mathrm{TH}$ for patients with non-shockable rhythms, OHCA of noncardiac origin and in older patients has been poor and indirect at best [10]. While TH should mitigate reperfusion injury in the brain, regardless of cause and initial heart rhythm, expanding $\mathrm{TH}$ to new patient groups could usurp valuable ICU resources without necessarily improving outcomes.

Based on this background information, we assessed the actual use of $\mathrm{TH}$ and the associated outcomes in a health system with early adoption and broad application of TH. More specifically, we analysed which patient and cardiac arrest factors that predicted use of $\mathrm{TH}$ and survival to discharge in adult unconscious OHCA patients with both cardiac and non-cardiac aetiologies admitted to the ICU.

\section{Material and Methods Study design and organisation}

This is a retrospective observational study of prospectively collected cardiac arrest and ICU registry data from 2004 to 2008 from the Oslo University Hospital Ullevål, Haukeland University Hospital Bergen and Stavanger University Hospital in Norway.

All three centres used a standardised post-resuscitation treatment protocol, including $\mathrm{TH}$ for unconscious patients and emergency percutaneous coronary intervention (PCI) for patients with ST-elevation myocardial infarction $[7,11]$. Prognostication in the study ICUs was primarily done based on clinical examination [4].

Patients were treated in medical, cardiac or general ICUs, and both non-invasive and invasive cooling methods were applied $[7,12]$. All together, the study sites served a population of approximately 1.3 million people with a combination of $\mathrm{TH}$ and emergency PCI.

The Norwegian Emergency Medical Service is regulated by governmental agencies with medical responsibility placed in local health trusts. Emergency dispatch centres coordinate the emergency response of ambulance units, hospital-based and emergency physician-led rapid response units, and general practitioners who are on call in local municipalities [13]. All of these units are called simultaneously when a patient suffers a presumed OHCA [13]. We followed the 2000 and 2005 guidelines from the European Resuscitation Council [14,15], with Norwegian adjustments $[14,16]$.

\section{Study population}

Between January 2004 and January 2008, we included all adult (age $>18$ years) OHCA patients admitted with ROSC to an ICU at one of the three study sites (Figure 1). The study population included patients who suffered OHCA from either cardiac or non-cardiac causes. Patients with a trauma-related aetiology were excluded. Only a few patients were admitted to the emergency department with ongoing cardiopulmonary resuscitation (CPR). These patients were included if ROSC was established in the emergency department; otherwise, they were accounted for as prehospital nonsurvivors and not included (Figure 1). Each of the three hospitals contributed about one-third of the patients included in this study.

\section{Data collection and definitions}

All study sites had a prehospital Utstein-style [17] cardiac arrest registry. Hospital data were obtained from intensive care quality assurance databases and the local Northern Hypothermia Network databases [5,18]. A medical condition was registered as co-morbidity if the patient was under current pharmacological treatment or required medical follow-up due to the disease. The data variables collected in the research database were based on a consensus protocol between the three participating study sites. Each study site was responsible for the verification of the local registered data before they were transferred anonymously to the research database of this study.

TH was registered as performed when a target temperature of $33^{\circ} \mathrm{C}\left( \pm 1^{\circ} \mathrm{C}\right)$ was obtained and kept for 12$24 \mathrm{~h}$. Both external and invasive methods were used to induce and maintain cooling $[12,19]$. No further details on the use of $\mathrm{TH}$ were collected. Good neurological function was defined as a Cerebral Performance Category of 1 or 2 at discharge from the hospital [17]. The calculation of the Cerebral Performance Category was based on information from the hospital charts and follow-up notes.

\section{Statistical analysis and ethical approval}

We used the chi-square test to examine differences in proportions for categorical variables. The nonparametric Kruskal-Wallis test was used to test for differences in means for continuous variables across groups. Logistic regression analysis was used to model the effect of 


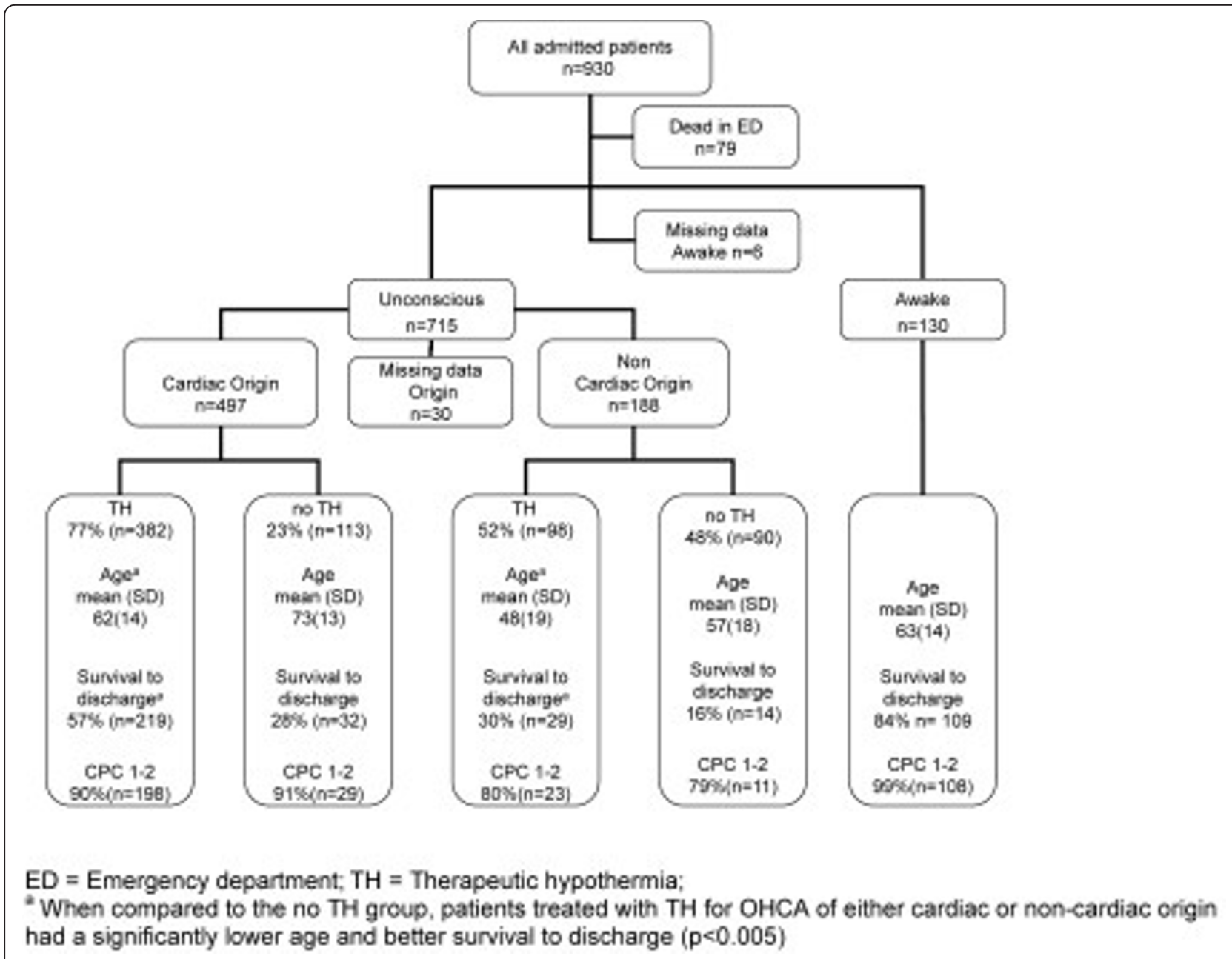

Figure 1 Flow chart of the 930 patients who had an OHCA and were admitted to the study hospitals between January 2004 and January 2008.

explanatory variables on dichotomous outcome variables. The outcome variables for this study were the use of TH and discharged alive from the hospital. Multivariable logistic regression models were constructed aided by backward stepwise variable selection. We tried both forward and backward selection and the same models were proposed. Variables with a $P$ value of $<0.25$ in univariable analyses were considered as candidates for inclusion in the multivariable model. Goodness of fit for the logistic regression model was verified by the Hosmer-Lemeshow test. Linearity in the log-odds ratio (OR) for continuous explanatory variables was verified by adding smooth spline terms. Possible medical relevant interaction terms between variables were tested.

The following factors were included as explanatory variables in the logistic regression analysis for the use of TH: age, gender, first registered heart rhythm, witnessed OHCA, performed bystander CPR, response time of the emergency medical system, origin of the OHCA, site of the OHCA and study site. The same explanatory variables and the use of $\mathrm{TH}$ and co-morbidities (coronary disease, hypertension, heart failure, diabetes mellitus and renal impairment) were included in the logistic regression analysis evaluating survival to hospital discharge.

A propensity score for the probability of a patient to receive $\mathrm{TH}$ was calculated with a logistic regression model based on Utstein template variables and medical relevant interaction terms among these. The logarithm of the odds of the propensity score was added as a covariate in the multivariable logistic regression model evaluating survival to discharge from the hospital $[20,21]$.

Missing data occurred in several variables examined in this study. We found it reasonable to assume that missing values are missing at random. This and the fact that the percentage of missing data was low justified using complete case analyses without introducing bias or noticeable reduced power. Information on the missing data is shown in the tables if the missing data comprise 
$>5 \%$ of all data. The numbers of complete datasets are reported for the multivariable analyses.

The data were entered into a FilemakerPro7 database (FileMaker, Inc.; USA) and Microsoft ${ }^{\circledR}$ Office Excel. Figures were constructed using SPSS 18.0, Microsoft ${ }^{\circledR}$ Office Excel and Power Point 2003 (Microsoft Corporation, USA). SPSS 18.0 (SPSS, Inc; USA) and R 2.15.0 2 (r-project, USA) were used for statistical analyses. Twosided $P$ values $<0.05$ were considered statistically significant.

The collection of local data was approved by the Norwegian Social Science Data Service. The Regional Ethics Committee in West Norway (REC West; University of Bergen) stated that use of such data was considered quality assurance and waived the use of individual informed consent.

\section{Results}

\section{Characteristics of the study population}

Of the 930 OHCA patients with ROSC admitted to the study hospitals, 715 patients remained unconscious and were admitted to the study ICUs. These 715 patients constituted the cohort assessed in this study (Figure 1). Table 1 gives an overview of the demographics and clinical baseline characteristics. Coronary disease (32\%), hypertension (27\%), heart failure (20\%), diabetes mellitus (13\%) and renal impairment (3\%) were the most common co-morbidities.

The overall use of $\mathrm{TH}$ was $70 \%$ (Table 1). While the majority $(77 \%)$ of patients with OHCA of cardiac origin were offered $\mathrm{TH}$, only half (52\%) of the patients with a non-cardiac origin were provided the same treatment $(P$ $<0.001$ ) (Figure 1). We found the same difference in use of $\mathrm{TH}$ when comparing patients with an initial shockable $(80 \%)$ and non-shockable rhythm (54\%) (Table 2). Overall use of emergency coronary angiography and PCI in the patients with a cardiac cause $(n=497)$ was $57 \%$.

The overall survival rate to hospital discharge was $42 \%$ (Table 1). The incidence of good cerebral outcome was $90 \%$ in patients surviving to discharge. Unadjusted survival to hospital discharge and the incidence of good cerebral outcome was similar between the three sites (Table 1). Further, unadjusted survival to discharge was significantly higher in the TH treated patients (Figure 1; Table 2 ). The oldest patients ( $>80$ years) had a significantly worse outcome than younger patients with only $18 \%$ of older patients surviving to hospital discharge (Figure 2). Only 33 (35\%) of the 94 patients aged $>80$ years received $\mathrm{TH}$. The corresponding number in the 31 female patients aged $>80$ years was five $(16 \%)$. Unadjusted survival in patients aged $>80$ years who received TH was not significantly higher than those that did not receive $\mathrm{TH}(21 \% v s .15 \%$, respectively, $P=0.426)$.

Overall, survivors had a significantly longer median length of ventilator treatment than non-survivors: $65 \mathrm{~h}$ (41-133 h) versus $52 \mathrm{~h}(18-111 \mathrm{~h})(P=0.001)$. Similarly, survivors also had a significantly longer median ICU stay (6 days versus 3 days, $P<0.001$ ).

\section{Predictors for use of TH and survival}

In a multivariable logistic regression model, we found witnessed arrest, an initial shockable rhythm, cardiac origin and bystander CPR to be positive predictors for the use of TH (Table 3a). On the other hand, increasing age and female gender predicted a lower utilisation of $\mathrm{TH}$ (Table 3a). After dividing the study population in

Table 1 Demographics and clinical characteristics.

\begin{tabular}{|c|c|c|c|c|c|}
\hline & All ICUs $n=715$ & ICU A $n=267$ & ICU B $n=201$ & ICU C $n=247$ & $P$ value \\
\hline Age, years mean (SD) & $61(17)$ & $59(17)$ & $62(17)$ & $63(17)$ & 0.006 \\
\hline Age $>=80 n(\%)$ & $95(13 \%)$ & $23(9 \%)$ & $35(17 \%)$ & $37(15 \%)$ & 0.013 \\
\hline Male sex $n(\%)$ & $522(73 \%)$ & $206(77 \%)$ & $153(76 \%)$ & $163(66 \%)$ & 0.009 \\
\hline Witnessed OHCA $n(\%)$ & $587(83 \%)$ & $222(83 \%)$ & $166(84 \%)$ & 199 (81\%) & 0.627 \\
\hline Bystander CPR $n$ (\%) & $458(66 \%)$ & $184(69 \%)$ & $142(74 \%)$ & $132(55 \%)$ & $<0.001$ \\
\hline Location OHCA Home $n$ (\%) & $331(47 \%)$ & $108(44 \%)$ & $111(55 \%)$ & $112(45 \%)$ & 0.006 \\
\hline $\begin{array}{l}\text { EMS Response time in minutes; Mean (SD) } \\
\text { Time to ROSC in witnessed OHCA minutes; Mean (SD) }\end{array}$ & $\begin{array}{l}9(5) \\
26(17)\end{array}$ & $\begin{array}{l}10(5) \\
30(20)\end{array}$ & $\begin{array}{l}9(6) \\
26(15)\end{array}$ & $\begin{array}{l}8(6) \\
21(13)\end{array}$ & $\begin{array}{l}0.007 \\
<0.001\end{array}$ \\
\hline First rhythm shockable $n(\%)$ & $430(62 \%)$ & $175(66 \%)$ & $126(68 \%)$ & $129(54 \%)$ & 0.003 \\
\hline Cardiac origin of OHCA $n(\%)$ & 497 (73\%) & $202(77 \%)$ & 149 (78\%) & $146(63 \%)$ & $<0.001$ \\
\hline $\mathrm{TH} n(\%)$ & 497 (70\%) & $208(78 \%)$ & $151(76 \%)$ & $138(56 \%)$ & $<0.001$ \\
\hline $\begin{array}{l}\text { EEG } n(\%) \\
\text { CCT } n(\%) \\
\text { SEP } n(\%)\end{array}$ & $\begin{array}{l}166(23 \%) \\
317(44 \%) \\
22(3 \%)\end{array}$ & $\begin{array}{l}108(40 \%) \\
128(48 \%) \\
0(0 \%)\end{array}$ & $\begin{array}{l}36(18 \%) \\
73(36 \%) \\
20(10 \%)\end{array}$ & $\begin{array}{l}24(10 \%) \\
116(47 \%) \\
2(1 \%)\end{array}$ & $\begin{array}{l}<0.001 \\
0.014 \\
<0.001\end{array}$ \\
\hline Survival to discharge $n(\%)$ & $301(42 \%)$ & $108(41 \%)$ & $89(44 \%)$ & $104(42 \%)$ & 0.747 \\
\hline Survival to discharge with CPC $1-2, n(\%)$ & $267(37 \%)$ & $94(35 \%)$ & $81(40 \%)$ & $92(37 \%)$ & 0.525 \\
\hline
\end{tabular}

$\mathrm{CCT}=$ Cranial computer tomography; CPC = Cerebral performance category; EEG = Electroencephalogram; EMS = Emergency medical system; ROSC = Return of spontaneous circulation; SD = Standard deviation; SEP = Somatosensory evoked potentials; $\mathrm{TH}=$ Therapeutic hypothermia 
Table 2 Demographics and clinical characteristics divided after initial rhythm $(n=715$, missing data for initial rhythm 21)

\begin{tabular}{|c|c|c|c|c|c|c|}
\hline & Shockable rhythm & & & Non-shockable rh & & \\
\hline & TH yes $(n=342)$ & TH no $(n=87)$ & $P$ value & TH yes $(n=143)$ & TH no $(n=120)$ & $P$ value \\
\hline Age, years Mean (SD) & $61(15)$ & $70(14)$ & $<0.001$ & $56(19)$ & $62(18)$ & 0.005 \\
\hline Male sex, $n(\%)$ & $283(83)$ & $58(67)$ & $<0.001$ & $98(69)$ & $68(57)$ & 0.047 \\
\hline Witness OHCA, $n(\%)$ & $313(92)$ & (84) & 0.027 & $101(71)$ & $82(68)$ & 0.696 \\
\hline Bystander CPR, $n(\%)$ & $246(72)$ & $48(55)$ & 0.022 & $97(68)$ & $54(45)$ & $<0.001$ \\
\hline Location OHCA home, $n$ (\%) & $147(43)$ & $32(37)$ & 0.295 & $54(38)$ & $52(43)$ & 0.667 \\
\hline EMS response time, min, mean (SD) & $9(5)$ & $9(6)$ & 0.519 & $10(9)$ & $9(6)$ & 0.360 \\
\hline Cardiac origin to OHCA, $n(\%)$ & $320(94)$ & $76(87)$ & 0.120 & $57(40)$ & $34(28)$ & 0.050 \\
\hline Survival to discharge, $n(\%)$ & $219(64)$ & $31(36)$ & $<0.001$ & $25(17)$ & $11(9)$ & 0.051 \\
\hline Survival to discharge with CPC $1-2, n(\%)$ & $191(56)$ & $28(32)$ & $<0.001$ & $20(14)$ & $9(8)$ & 0.094 \\
\hline
\end{tabular}

$\mathrm{CPC}=$ Cerebral performance category; EMS = Emergency medical system; SD = Standard deviation; TH = Therapeutic hypothermia .

two groups according to initial rhythm (Table $3 \mathrm{~b}$ and $3 c$ ), we found that increasing age and female gender remained negative predictors for $\mathrm{TH}$ use in the subgroup of patients with shockable rhythm (Table $3 \mathrm{~b}$ ). In the subgroup of patients with non-shockable rhythms, however, female gender did not remain a significant predictor for TH use, while study ICU became a significant predictor (Table 3c).

In terms of survival, cardiac origin and an initial shockable rhythm were positive predictors of survival, while increasing age, female gender and diabetes mellitus were negative predictors of survival (Table 4). When analysing data from patients with witnessed OHCA only ( $n=587 ; 82 \%$ of all patients), we could also include time to ROSC as a variable in the logistic regression model. Doing this, study site as a significant positive predictor for survival (Table 4) to discharge disappeared while time to ROSC became a significant factor (Table 5 ). The predictive power of the other factors, including $\mathrm{TH}$, remained the same (Table 5).

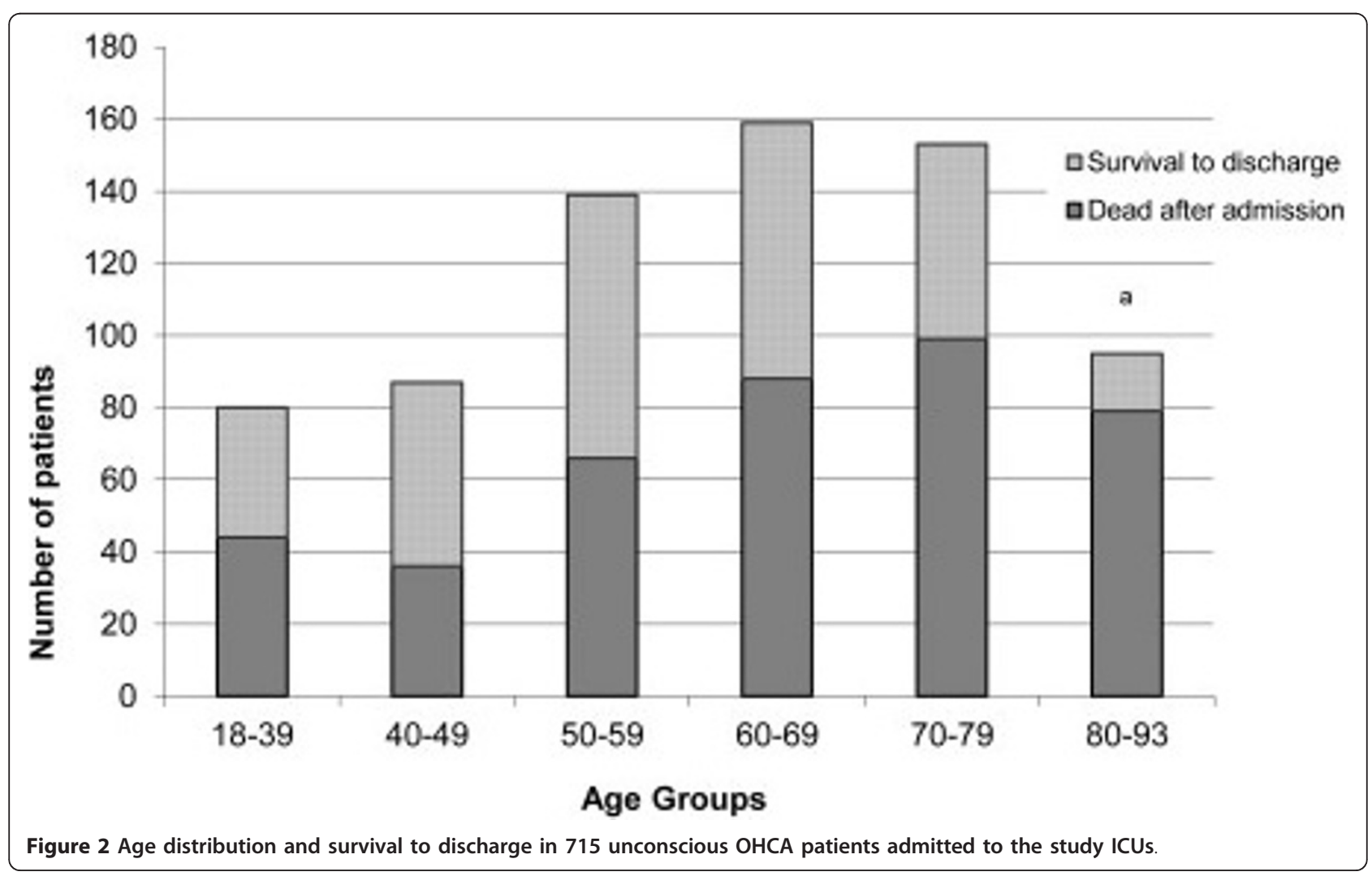


Table 3a Predictors for the use of therapeutic hypothermia in all patients ( $n=715$; missing data 68 ).

\begin{tabular}{llll}
\hline & OR & $\mathbf{9 5 \% ~ C l}$ & $\boldsymbol{P}$ value \\
\hline Age (one additional year) & 0.96 & $0.94-0.97$ & $<0.001$ \\
Witnessed arrest & 2.08 & $1.26-3.40$ & 0.004 \\
Female gender & 0.65 & $0.43-0.97$ & 0.038 \\
Bystander CPR & 2.30 & $1.57-3.39$ & 0.001 \\
Shockable rhythm & 1.92 & $1.20-3.09$ & 0.007 \\
Cardiac origin & 2.92 & $1.70-5.02$ & $<0.001$ \\
\hline
\end{tabular}

$\mathrm{CPR}=$ Cardiopulmonary resuscitation; multivariable logistic regression model with adjusted odds ratio $(\mathrm{OR})$

Table 3b Predictors for the use of therapeutic hypothermia in patients with shockable rhythm $(n=421$; missing data 9)

\begin{tabular}{llll}
\hline & OR & $\mathbf{9 5 \% ~ C I}$ & $\boldsymbol{P}$ value \\
\hline Age (one additional year) & 0.95 & $0.93-0.97$ & $<0.001$ \\
Witnessed arrest & 2.36 & $1.11-4.99$ & 0.025 \\
Female gender & 0.48 & $0.28-0.86$ & 0.013 \\
Bystander CPR & 1.99 & $1.18-3.35$ & $<0.001$ \\
\hline
\end{tabular}

CPR = Cardiopulmonary resuscitation; multivariable logistic regression model with adjusted odds ratio $(\mathrm{OR})$

Table 3c Predictors for the use of therapeutic hypothermia in patients with a non-shockable rhythm ( $n=235$; missing data 29)

\begin{tabular}{llll}
\hline & OR & $\mathbf{9 5 \% ~ C I}$ & $\boldsymbol{P}$ value \\
\hline Age(one additional year) & 0.97 & $0.95-0.99$ & 0.001 \\
Bystander CPR & 2.36 & $1.33-4.2$ & 0.003 \\
Cardiac origin & 2.89 & $1.48-5.66$ & 0.002 \\
ICU - Reference A & 0.8 & $0.36-1.77$ & 0.79 \\
ICU B & & & \\
ICU C & 0.36 & $0.19-0.68$ & 0.002 \\
\hline
\end{tabular}

CPR = Cardiopulmonary resuscitation; multivariable logistic regression model with adjusted odds ratio (OR)

When testing the significance of clinical relevant interactions between variables used in the logistic regression analyses, we found a significant interaction between shockable rhythm and gender. For males the OR for survival for shockable rhythm was 9.01 (95\% CI 4.80 to 16.91), while for females the same OR was 2.75 (95\% CI 1.14 to 6.62$)$. When including this interaction term in the logistic regression model there is no further significant effect of sex and the effect of the other variables in Table 4 remained unchanged. We did not find any such interactions for study site. Further, there was not a significant interaction between $\mathrm{TH}$ and initial rhythm for survival.

Because the application of $\mathrm{TH}$ was based on the treating physician's decision and not random, we also included a propensity score for use of $\mathrm{TH}$ as a covariate in the multivariable analysis of possible predictors of survival to discharge. However, this did not change the
Table 4 Predictors of survival to discharge in all patients ( $n=715$; missing data 96)

\begin{tabular}{llll}
\hline & OR & $\mathbf{9 5 \% ~ C l}$ & $\boldsymbol{P}$ value \\
\hline Age (one additional year) & 0.96 & $0.94-0.97$ & $<0.001$ \\
Female gender & 0.57 & $0.36-0.92$ & 0.022 \\
Cardiac origin & 2.64 & $1.36-5.10$ & 0.001 \\
Diabetes mellitus & 0.35 & $0.19-0.65$ & 0.001 \\
Shockable rhythm & 6.50 & $3.77-11.38$ & $<0.001$ \\
TH & 1.91 & $1.18-3.06$ & 0.007 \\
ICU - Reference A & 1.08 & $0.68-1.72$ & 0.732 \\
ICU B & & & \\
ICU C & 2.35 & $1.46-3.75$ & $<0.001$ \\
\hline
\end{tabular}

Multivariable logistic regression model with adjusted odds ratio (OR); $\mathrm{TH}=$ Therapeutic hypothermia

adjusted OR for the effect of TH compared to the analysis above (Table 4 and 5) and is therefore not further reported.

When analysing factors predicting survival in patients with shockable and non-shockable rhythm separately, the overall results for patients with shockable rhythm ( $n$ $=430$ ) did not change compared to the total cohort. In the smaller subgroup of patients with a non-shockable first rhythm $(n=264)$, however, use of TH (OR 1.46; 95\% CI 0.56 to 3.78 ) did not remain a significant predictor for survival any longer. Age (OR 0.97; 95\% CI 0.95 to 0.99 ) and cardiac origin (OR $2.95 ; 95 \%$ CI 0.1 .27 to 6.99) were the only independent predictors for survival to discharge in this subgroup.

\section{Discussion}

We studied the use of $\mathrm{TH}$ and related outcomes in unconscious patients who suffered an OHCA from either cardiac or non-cardiac causes and were admitted to the ICU. TH was used in $70 \%$ of the patients. However, patients with an initial non-shockable rhythm or a non-cardiac cause of the OHCA were significantly less likely to receive $\mathrm{TH}$. The overall survival to discharge was $42 \%$, with $90 \%$ of patients surviving to discharge having a good neurologic outcome, defined as a CPC of 1-2 [17]. Known positive prognostic factors, such as a

Table 5 Predictors of survival to discharge in patients with witnessed OHCA ( $n=587$; missing data 92)

\begin{tabular}{llll}
\hline & OR & $\mathbf{9 5 \% ~ C l}$ & $\boldsymbol{P}$ value \\
\hline Age (one additional year) & 0.95 & $0.93-0.96$ & $<0.001$ \\
Female gender & 0.47 & $0.27-0.80$ & 0.007 \\
Cardiac origin & 3.11 & $1.43-6.77$ & 0.004 \\
Diabetes mellitus & 0.47 & $0.24-0.92$ & 0.029 \\
Shockable rhythm & 5.77 & $3.04-10.94$ & $<0.001$ \\
Time to ROSC (one additional minute) & 0.95 & $0.93-0.96$ & $<0.001$ \\
TH & 1.87 & $1.05-3.31$ & 0.033 \\
\hline
\end{tabular}

Multivariable logistic regression model with adjusted odds ratio (OR); ROSC = Return of spontaneous circulation; $\mathrm{TH}=$ Therapeutic hypothermia 
witnessed arrest, bystander CPR, initial shockable rhythm and cardiac cause of OHCA were all positive predictors of $\mathrm{TH}$ use as well as survival.

After correcting for the other prognostic factors, the use of $\mathrm{TH}$ was an independent predictor of improved survival in the whole study population. However, when performing a subgroup analysis of patients with nonshockable rhythms, use of $\mathrm{TH}$ did not remain a significant predictor of survival. One reason for this can be lower power of the analysis due to the inevitably lower number of patients in such subgroup analysis. It is also important to emphasise that the expected survival rate and thereby the potential impact of $\mathrm{TH}$ is much lower for patients with a non-shockable rhythm, as seen both in our study and other reports [22-25]. Some authors have found no benefits of TH in patients with nonshockable rhythm $[26,27]$ while others have concluded that a positive impact on survival is likely $[23,25,28,29]$. The use of TH in such patients was recommended by ILCOR both in 2005 and 2010 [30,31]. In Norway, the use of $\mathrm{TH}$ in patients with an initial non-shockable rhythm has been recommended since 2004 [8], but only $50 \%$ of such patients were actually cooled in our study. In a recent study covering all Finnish ICUs, the authors detected large and unexplained differences in local cooling practice [24]. They also found use of TH in onethird of patients with an initial non-shockable rhythm, despite the national recommendation not to cool such patients [24]. We think this underlines the present uncertainty of local cooling practices and its effect on outcome. We need more and larger studies to fully understand the treatment potential of $\mathrm{TH}$ in various subgroups of post-resuscitation patients [23].

We found that increasing age predicted less use of $\mathrm{TH}$, but also a lower survival. In the recent FINNRESUSCI study, advanced age was a common reason for withholding $\mathrm{TH}$ in unconscious OHCA patients [24]. The evidence showing benefits of $\mathrm{TH}$ in older patients is sparse. In a single-centre study of $\mathrm{TH}$ in patients fulfilling the criteria for inclusion in the original HACA trial [1], older age ( $\geq 80$ years) was associated with a lower survival [32]. Still, $50 \%$ of the older patients undergoing TH survived with good cerebral outcome. Previous studies have shown that emergency and intensive care physicians are reluctant to use ICU resources in older patients, and it has been discussed whether this represent age discrimination or sensible resource allocation $[33,34]$. It may be argued that $\mathrm{TH}$ use in the present study was not associated with a higher survival rate in the oldest age group ( $\geq 80$ years). However, the total number of older patients treated with $\mathrm{TH}$ was low, and there are still healthy older patients that might benefit from $\mathrm{TH}$. Therefore, a more liberal use of $\mathrm{TH}$ may be indicated [34].
Surprisingly, we found female gender to be an independent predictor both for decreased TH use and survival in patients with a shockable rhythm. Previous studies have found lower utilisation of invasive procedures, such as percutaneous coronary intervention, in female patients [35]. Different age distributions and comorbidity related to gender may partly explain the differences in care provided and outcome in women versus men [36-38]. Recent studies in the ICU setting have provided conflicting results regarding interaction between gender, medical interventions and survival $[39,40]$. We are not aware of any previous studies looking at this aspect in post cardiac arrest patients. Since we corrected for age, prehospital cardiac arrest factors and co-morbidity in our logistic regression model, it is concerning that female gender remained a negative predictor of survival in patients with a shockable rhythm. In contrast, recent prehospital studies reported female gender to either be a positive predictor of survival or be without predictive power [41,42]. Gender has been highlighted as an important factor to address when trying to improve overall cardiac care [38]. Our results may indicate underutilisation of $\mathrm{TH}$ in female patients. Our results should definitely lead to more research on the impact of age and gender on the use of $\mathrm{TH}$ and the associated outcomes.

We found study site to be an independent predictor for the use of $\mathrm{TH}$ in the subgroup of patients with non-shockable rhythm. This finding is reflected in the overall lower use of $\mathrm{TH}$ in this ICU. Study site was also an independent predictor of survival in the logistic regression model including the whole cohort. A recent German study [43] found significant differences in survival in OHCA patients depending on what kind of hospital they were brought to. All our hospitals offered emergency coronary angiography and were by definition cardiac arrest centres [44]. Differences in prehospital factors [45] are therefore a more likely explanation for the difference in survival [45]. Compared to the other two ICUs, patients from the ICU with the improved odds of survival had significantly shorter EMS response times, as well as shorter times to ROSC. Time to ROSC is a very important predictor of survival but only available in patients with witnessed OHCA [46]. We therefore analysed patients with witnessed OHCA (82\% of total cohort) separately. Doing this, we found that time to ROSC but not study site remained a significant predictor of survival. We think this finding strongly indicates that differences in prehospital factors affected hospital mortality in our study. Comatose OHCA patients most likely entered the ICU with a different baseline probability of survival due to differences in resuscitation times [45-48]. 
Since the use of TH was at the physician discretion in individual patients we tried to adjust for factors predicting the use of $\mathrm{TH}$ in the individual patient by introducing a propensity score as a covariate in the logistic regression model on survival $[20,21]$. However, this did not change the estimated effect of TH. Nevertheless, the observational study design only allowed us to show statistical associations and not prove causative relationships. Only prospective, randomised controlled trials can prove the efficacy of $\mathrm{TH}$ in subgroups of patients with OHCA admitted to the ICU. Still, well-designed observational studies may provide insight into everyday use of $\mathrm{TH}$ and help improve clinical practice [49].

\section{Limitations}

There are several limitations to our retrospective and registry based study. Despite an agreement on definitions for the different data points, data verification may have varied from site to site. This may have changed the grouping of patients and affected the logistic regression model. Although we adjusted for other known factors when modelling the relation between use of $\mathrm{TH}$ and survival, the validity of the resulting models may have been weakened by unknown or unobserved factors not included. Further, despite the similarities in organisation of the ICUs studied, there may have been differences in the medical management and hospital policy not accounted for. It is known that withdrawal of life-sustaining therapy is a major factor of death in post cardiac arrest care and that early withdrawal of intensive care may be a problem $[48,50]$. The overall low use of objective prognostic tools in our patients was in accordance with common practice in Norwegian ICUs at the time of the study [4]. Still, we cannot fully rule out differences in clinical management that may have affected patient outcome in the study ICUs. We defined TH as reaching the targeted temperature for 12-24 h. TH may have been attempted unsuccessfully in more patients. The fact that we only followed patients to hospital discharge may also be considered a limitation of the present study.

Finally, we studied patients from three different cardiac arrest centres [44], but only from one country. The generalisability of our results to other countries and hospital systems may be questioned. Still, compared to other registry-based studies [46,51], a major strength of our study is that we included consecutively admitted comatose patients over a defined time period.

\section{Conclusion}

$\mathrm{TH}$ was used in the majority of unconscious OHCA patients admitted to the ICU, but actual use varied significantly between subgroups. Increasing age predicted both a decreased utilisation of $\mathrm{TH}$ as well as a lower survival. Further, in patients with a shockable rhythm female gender also predicted a lower use of $\mathrm{TH}$ and poorer survival. Our results indicate an underutilisation of TH in some subgroups. Hence, more research on factors affecting $\mathrm{TH}$ use and the associated outcomes in subgroups of post-resuscitation patients is needed.

\section{Key messages}

- Older age predicted a lower use of therapeutic hypothermia as well as a lower survival in unconscious OHCA patients admitted to the ICU.

- In patients with an initial shockable rhythm, female gender predicted a lower utilisation of therapeutic hypothermia and a lower survival to hospital discharge.

- The role of therapeutic hypothermia in patients with an initial non-shockable rhythm is still not fully elucidated.

\section{Abbreviations}

$\mathrm{Cl}$ : Confidence interval; CPR: Cardio pulmonary resuscitation; ICU: Intensive care unit; OHCA: Out-of-hospital cardiac arrest; OR: Odds ratio; PCl: Percutaneous coronary intervention; ROSC: Return-of-spontaneous circulation; $\mathrm{TH}$ : Therapeutic hypothermia

\section{Competing interests}

The authors declare that they have no competing interests.

\section{Authors' contributions}

TWL contributed to the design of the study, took part in the data acquisition, built the database and performed the statistical analysis, and drafted the manuscript. $J$ and KS made substantial contribution to the design of the study took part in data acquisition and helped draft the manuscript. JTK contributed to the study design, provided statistical support and helped draft the manuscript. AlL, JKH and TD contributed to the design of the study, took part in data acquisition and helped draft the manuscript. ES conceived of the study, participated in its design, coordination and statistical analysis, and helped draft the manuscript. All authors read and approved the final manuscript for publication.

\section{Acknowledgements}

We would like to thank Wenche T. Mathiesen and Conrad Bjørshol for help with data acquisition and fruitful discussions.

\section{Authors' details}

${ }^{1}$ Department of Anaesthesiology and Intensive Care, Stavanger University Hospital, Norway. ${ }^{2}$ Department of Heart Disease, Haukeland University Hospital, Bergen, Norway. ${ }^{3}$ Department of Anaesthesiology, Division of Emergencies and Critical Care, Oslo University Hospital, Norway.

${ }^{4}$ Department of Cardiology, Division of Internal Medicine, Stavanger University Hospital, Norway. ${ }^{5}$ Department of Clinical Medicine, University of Bergen, Norway. ${ }^{6}$ Department of Mathematics and Natural Sciences, University of Stavanger, Norway. ${ }^{7}$ Department of Anaesthesiology and Intensive Care, Haukeland University Hospital, Bergen, Norway. ${ }^{8}$ Department of Research and Development, Division of Emergencies and Critical Care, Oslo University Hospital, Norway.

Received: 2 March 2013 Revised: 31 May 2013 Accepted: 23 July 2013 Published: 23 July 2013

\section{References}

1. Bernard SA, Gray TW, Buist MD, Jones BM, Silvester W, Gutteridge G, Smith K: Treatment of comatose survivors of out-of-hospital cardiac arrest with induced hypothermia. N Engl J Med 2002, 346:557-563.

2. Hypothermia after Cardiac Arrest Study Group: Mild therapeutic hypothermia to improve the neurologic outcome after cardiac arrest. $N$ Engl J Med 2002, 346:549-556. 
3. Nolan JP, Morley PT, Vanden Hoek TL, Hickey RW, Kloeck WG, Billi J, Böttiger BW, Morley PT, Nolan JP, Okada K, Reyes C, Shuster M, Steen PA, Weil MH, Wenzel V, Hickey RW, Carli P, Vanden Hoek TL, Atkins D, International Liaison Committee on Resuscitation: Therapeutic hypothermia after cardiac arrest: an advisory statement by the advanced life support task force of the International Liaison Committee on Resuscitation. Circulation 2003, 108:118-121.

4. Busch M, Soreide E: Prognostication after out-of-hospital cardiac arrest, a clinical survey. Scand J Trauma Resusc Emerg Med 2008, 16:9.

5. Busch M, Soreide E, Lossius HM, Lexow K, Dickstein K: Rapid implementation of therapeutic hypothermia in comatose out-of-hospital cardiac arrest survivors. Acta Anaesthesiol Scand 2006, 50:1277-1283.

6. Soreide E, Sunde K: Therapeutic hypothermia after out-of hospital cardiac arrest: how to secure worldwide implementation. Curr Opin Anaesthesiol 2008, 21:209-215.

7. Sunde K, Pytte M, Jacobsen D, Mangschau A, Jensen LP, Smedsrud C, Draegni T, Steen PA: Implementation of a standardised treatment protocol for post resuscitation care after out-of-hospital cardiac arrest. Resuscitation 2007, 73:29-39.

8. Sunde $K$, Soreide E, Jacobsen D, Steen PA: [Therapeutic hypothermia after cardiac arrest saves more lives!]. Tidsskr Nor Laegeforen 2004, 124:925-926.

9. Hovdenes J, Laake JH, Aaberge L, Haugaa H, Bugge JF: Therapeutic hypothermia after out-of-hospital cardiac arrest: experiences with patients treated with percutaneous coronary intervention and cardiogenic shock. Acta Anaesthesiol Scand 2007, 51:137-142.

10. Sterz F, Holzer M, Roine R, Zeiner A, Losert H, Eisenburger P, Uray T, Behringer W: Hypothermia after cardiac arrest: a treatment that works. Curr Opin Crit Care 2003, 9:205-210.

11. Larsen Al, Melberg TH, Bonarjee V, Barvik S, Nilsen DW: Change to a primary $\mathrm{PCl}$ program increases number of patients offered reperfusion therapy and significantly reduces mortality: a real life experience evaluating the initiation of a primary $\mathrm{PCl}$ service at a single center without on site heart surgery in Western Norway. Int J Cardio/ 2008 127:208-213.

12. Våga $A$, Busch $M$, Karlsen $T E$, Nilsen $O B$, Soreide $E$ : A pilot study of key nursing aspects with different cooling methods and devices in the ICU. Resuscitation 2008, 76:25-30.

13. Langhelle A, Lossius HM, Silfvast T, Bjornsson HM, Lippert FK, Ersson A Soreide E: International EMS Systems: the Nordic countries. Resuscitation 2004, 61:9-21.

14. Nolan JP, Deakin CD, Soar J, Bottiger BW, Smith G: European Resuscitation Council guidelines for resuscitation 2005. Section 4. Adult advanced life support. Resuscitation 2005, , Suppl 1: S39-86.

15. Part 1: introduction to the International Guidelines 2000 for CPR and ECC. A consensus on science. European Resuscitation Council. Resuscitation 2000, 46:3-15.

16. Lexow K, Sunde K: Why Norwegian 2005 guidelines differs slightly from the ERC guidelines. Resuscitation 2007, 72:490-492.

17. Jacobs I, Nadkarni V, Bahr J, Berg RA, Billi JE, Bossaert L, Cassan P, Coovadia A, D'Este K, Finn J, Halperin H, Handley A, Herlitz J, Hickey R, Idris A, Kloeck W, Larkin GL, Mancini ME, Mason P, Mears G, Monsieurs K, Montgomery W, Morley P, Nichol G, Nolan J, Okada K, Perlman J, Shuster M, Steen PA, Sterz F, et al: Cardiac arrest and cardiopulmonary resuscitation outcome reports: update and simplification of the Utstein templates for resuscitation registries. A statement for healthcare professionals from a task force of the international liaison committee on resuscitation (American Heart Association, European Resuscitation Council, Australian Resuscitation Council, New Zealand Resuscitation Council, Heart and Stroke Foundation of Canada, InterAmerican Heart Foundation, Resuscitation Council of Southern Africa). Resuscitation 2004, 63:233-249.

18. The Northern Hypothermia Registry. [http://www.scctg.org/NHN/ NHNWelcome.htm], Accessed on December10th 2011.

19. Holzer M: Devices for rapid induction of hypothermia. Eur J Anaesthesiol Supp/ 2008, 42:31-38.

20. D'Agostino RB: Propensity scores in cardiovascular research. Circulation 2007, 115:2340-2343

21. Williamson E, Morley R, Lucas A, Carpenter J: Propensity scores: from naive enthusiasm to intuitive understanding. Stat Methods Med Res 2012, 21:273-293.

22. Martinell $L$, Larsson $M$, Bang A, Karlsson $T$, Lindqvist J, Thoren AB, Herlitz J: Survival in out-of-hospital cardiac arrest before and after use of advanced postresuscitation care: a survey focusing on incidence, patient characteristics, survival, and estimated cerebral function after postresuscitation care. Am J Emerg Med 2010, 28:543-551.

23. Sandroni C, Cavallaro F, Antonelli M: Therapeutic hypothermia: is it effective for non-VF/VT cardiac arrest? Crit Care 2013, 17:215.

24. Vaahersalo J, Hiltunen P, Tiainen M, Oksanen T, Kaukonen KM, Kurola J, Ruokonen E, Tenhunen J, Ala-Kokko T, Lund V, Reinikainen M, Kiviniemi O, Silfvast T, Kuisma M, Varpula T, Pettilä V, FINNRESUSCI Study Group: Therapeutic hypothermia after out-of-hospital cardiac arrest in Finnish intensive care units: the FINNRESUSCI study. Intensive Care Med 2013, 39:826-837.

25. Xiao G, Guo Q, Shu M, Xie X, Deng J, Zhu Y, Wan C: Safety profile and outcome of mild therapeutic hypothermia in patients following cardiac arrest: systematic review and meta-analysis. Emerg Med J 2013, 30:91-100.

26. Dumas F, Grimaldi D, Zuber B, Fichet J, Charpentier J, Pène F, Vivien B, Varenne O, Carli P, Jouven X, Empana JP, Cariou A: Is hypothermia after cardiac arrest effective in both shockable and nonshockable patients? Insights from a large registry. Circulation 2011, 123:877-886.

27. Rittenberger JC, Callaway CW: Muddy waters: Hypothermia does not work? Resuscitation 2011, 82:1120-1.

28. Kim YM, Yim HW, Jeong SH, Klem ML, Callaway CW: Does therapeutic hypothermia benefit adult cardiac arrest patients presenting with nonshockable initial rhythms? A systematic review and meta-analysis of randomized and non-randomized studies. Resuscitation 2012, 83:188-196.

29. Lundbye JB, Rai M, Ramu B, Hosseini-Khalili A, Li D, Slim HB, Bhavnani SP, Nair SU, Kluger J: Therapeutic hypothermia is associated with improved neurologic outcome and survival in cardiac arrest survivors of nonshockable rhythms. Resuscitation 2012, 83:202-207.

30. 2005 International Consensus on Cardiopulmonary Resuscitation and Emergency Cardiovascular Care Science with Treatment Recommendations. Part 4: Advanced life support. Resuscitation 2005, 67:213-247.

31. Koster RW, Sayre MR, Botha M, Cave DM, Cudnik MT, Handley AJ, Hatanaka T, Hazinski MF, Jacobs I, Monsieurs K, Morley PT, Nolan JP, Travers AH: Part 5: Adult basic life support: 2010 International consensus on cardiopulmonary resuscitation and emergency cardiovascular care science with treatment recommendations. Resuscitation 2010, , Suppl 1: e48-70.

32. Busch M, Søreide E: Should advanced age be a limiting factor in providing therapeutic hypothermia to cardiac arrest survivors? A singlecenter observational study. Ther Hypothermia Temp Manag 2011, 1:29-32.

33. Garrouste-Orgeas M, Boumendil A, Pateron D, Aergerter P, Somme D, Simon T, Guidet B, Group I-C: Selection of intensive care unit admission criteria for patients aged 80 years and over and compliance of emergency and intensive care unit physicians with the selected criteria: An observational, multicenter, prospective study. Crit Care Med 2009, 37:2919-2928.

34. Sprung CL, Artigas A, Kesecioglu J, Pezzi A, Wiis J, Pirracchio R, Baras M, Edbrooke DL, Pesenti A, Bakker J, Hargreaves C, Gurman G, Cohen SL, Lippert A, Payen D, Corbella D, lapichino G: The Eldicus prospective, observational study of triage decision making in European intensive care units. Part II: intensive care benefit for the elderly. Crit Care Med 2012, 40:132-138.

35. Haglund B, Koster M, Nilsson T, Rosen M: Inequality in access to coronary revascularization in Sweden. Scand Cardiovasc J 2004, 38:334-339.

36. Thompson CA, Kaplan AV, Friedman BJ, Jayne JE, Gerling BR, Niles NW, Hettleman BD, Robb JF: Gender-based differences of percutaneous coronary intervention in the drug-eluting stent era. Catheter Cardiovasc Interv 2006, 67:25-31.

37. Eapen ZJ, Peterson ED, Fonarow GC, Sanders GD, Yancy CW, Sears SF Jr, Carlson MD, Curtis AB, Hall LL, Hayes DL, Hernandez AF, Mirro M, Prystowsky E, Russo AM, Thomas KL, Al-Khatib SM: Quality of care for sudden cardiac arrest: Proposed steps to improve the translation of evidence into practice. Am Heart J 2011, 162:222-231.

38. Poon S, Goodman SG, Yan RT, Bugiardini R, Bierman AS, Eagle KA Johnston N, Huynh T, Grondin FR, Schenck-Gustafsson K, Yan AT: Bridging the gender gap: Insights from a contemporary analysis of sex-related differences in the treatment and outcomes of patients with acute coronary syndromes. Am Heart J 2012, 163:66-73.

39. Mahmood K, Eldeirawi K, Wahidi MM: Association of gender with outcomes in critically ill patients. Crit Care 2012, 16:R92. 
40. Nachtigall I, Tafelski S, Rothbart A, Kaufner L, Schmidt M, Tamarkin A, Kartachov M, Zebedies D, Trefzer T, Wernecke KD, Spies C: Gender-related outcome difference is related to course of sepsis on mixed ICUs: a prospective, observational clinical study. Crit Care 2011, 15:R151.

41. Adielsson A, Hollenberg J, Karlsson T, Lindqvist J, Lundin S, Silfverstolpe J, Svensson L, Herlitz J: Increase in survival and bystander CPR in out-ofhospital shockable arrhythmia: bystander CPR and female gender are predictors of improved outcome. Experiences from Sweden in an 18year perspective. Heart 2011, 97:1391-1396.

42. Bray JE, Stub D, Bernard S, Smith K: Exploring gender differences and the "oestrogen effect" in an Australian out-of-hospital cardiac arrest population. Resuscitation 2013, 84:957-963.

43. Wnent J, Seewald S, Heringlake M, Lemke H, Brauer K, Lefering R, Fischer M, Jantzen T, Bein B, Messelken M, Gräsner JT: Choice of hospital after out-ofhospital cardiac arrest - a decision with far-reaching consequences: a study in a large German city. Crit Care 2012, 16:R164.

44. Mancini ME, Soar J, Bhanji F, Billi JE, Dennett J, Finn J, Ma MH, Perkins GD, Rodgers DL, Hazinski MF, Jacobs I, Morley PT: Part 12: Education, implementation, and teams: 2010 International Consensus on Cardiopulmonary Resuscitation and Emergency Cardiovascular Care Science With Treatment Recommendations. Circulation 2010, , Suppl 2: S539-581.

45. Sasson C, Rogers MA, Dahl J, Kellermann AL: Predictors of survival from out-of-hospital cardiac arrest: a systematic review and meta-analysis. Circ Cardiovasc Qual Outcomes 2010, 3:63-81.

46. Nielsen N, Hovdenes J, Nilsson F, Rubertsson S, Stammet P, Sunde K, Valsson F, Wanscher M, Friberg H, Hypothermia N: Outcome, timing and adverse events in therapeutic hypothermia after out-of-hospital cardiac arrest. Acta Anaesthesiol Scand 2009, 53:926-934.

47. Oddo M, Ribordy V, Feihl F, Rossetti AO, Schaller MD, Chiolero R, Liaudet L: Early predictors of outcome in comatose survivors of ventricular fibrillation and non-ventricular fibrillation cardiac arrest treated with hypothermia: a prospective study. Crit Care Med 2008, 36:2296-2301.

48. Tomte O, Andersen GO, Jacobsen D, Draegni T, Auestad B, Sunde K: Strong and weak aspects of an established post-resuscitation treatment protocol-A five-year observational study. Resuscitation 2011, 82:1186-1193.

49. Rea TD, Dumas F: Resuscitation science: a role for observation? Resuscitation 2012, 83:281-282.

50. Dragancea I, Rundgren M, Englund E, Friberg H, Cronberg T: The influence of induced hypothermia and delayed prognostication on the mode of death after cardiac arrest. Resuscitation 2013, 84:337-342.

51. Arrich J, European Resuscitation Council Hypothermia After Cardiac Arrest Registry Study G: Clinical application of mild therapeutic hypothermia after cardiac arrest. Crit Care Med 2007, 35:1041-1047.

\section{doi:10.1186/cc12826}

Cite this article as: Lindner et al:. Factors predicting the use of therapeutic hypothermia and survival in unconscious out-of-hospital cardiac arrest patients admitted to the ICU. Critical Care 2013 17:R147.

\section{Submit your next manuscript to BioMed Central and take full advantage of:}

- Convenient online submission

- Thorough peer review

- No space constraints or color figure charges

- Immediate publication on acceptance

- Inclusion in PubMed, CAS, Scopus and Google Scholar

- Research which is freely available for redistribution 